\title{
STABILITY AND GENETIC DIVERSITY FOR YIELD AND YIELD COMPONENTS IN SOME EGYPTIAN COTTON GENOTYPES
}

\author{
SAMIA E. ALI
}

Cotton Research Institute, ARC, Giza, Egypt.

(Manuscript received 18 June 2017)

\begin{abstract}
$\mathrm{T}$ he present investigation aimed to determine phenotypic and genotypic stability of some long staple cotton genotypes using stability statistical analysis. Also to identify the range of similarity and diversity between these genotypes. Twenty one genotypes besides three check varieties, (promising cross [(G.89 x Karshenky) x G.86] x G.94 and two check genotypes: G.94 and G.86, were evaluated under six locations i.e.,(Kafr El-Sheikh, ElDakahleia, El-Monofeia, El-Sharkeia ,El-Gharbeia and El Behera) during 2016 season for yield and its components. The results showed that variances due to genotypes, environments and genotype $x$ environment interaction were highly significant for all studied traits except genotypes for boll weight was significant, which indicated that these genotypes interacted differentially with environments. The heritability values were high for studied traits (over $50 \%$ ) indicating that the phenotypic selection for these strains could be highly effective. The results of phenotypic stability showed that the genotypes No.1 and No. 18 for boll weight, No.9 for seed cotton yield and No.7 for lint cotton yield had phenotypic stability. Average genotypic stability recorded by genotypes No.12,21 and 23the (chick varietyG.94) for all studied traits and surpassed chick varietyG.86 .Nine genotypes No.1,2,5,12,13,18,21,22 the(promising cross [(G.89 x Karsh.) x G.86] x G.94 and 23 exhibited average level of stability also genotypes No.7,8 and 14 observed above average of stability at probability level of 0.95 for boll weight, while twelve genotypes No.
\end{abstract} $3,7,9,10,12,14,15,19,20,21,23$ (G.94) and 24(G.86) exhibited average level of stability for seed cotton yield and lint yield most of them surpassed the overall Mean and chick variety G.86.As for similarity, the results showed that the genotype No.12 and 22 revealed the lower distance 3.411 with similarity level $98.91 \%$, while the genotype No.8 and node 22( all the genotypes) showed the highly distance 69.073 with similarity level $77.83 \%$. The cotton breeder could choose the genotypes which have the highest stability, yield and fiber quality to be used as commercial varieties. According to the previous results the cross [(G.89 x Karsh.) x G.86] xG.94 could be good substitutes to G.94 variety. Also genotypesNo.14 $\mathrm{F}_{8} 632 / 2015$ descending from the cross (G.89 xG.86) $x\left[(G .83 \times 80) \times\right.$ G.89] ,No.18 $F_{10661 / 2015}$ descending from the cross G.85 $\times(G .89 \times$ G.86) and No.1 descending from the cross G.94 x [(G.89 x Pima S6) x G.86] could be good substitutes to the variety G.86.

Therefore the genotype No.8 $F_{8} 609 / 2015$ descending from the cross (G.89 x Pima S6) $x\{[($ Bah.105 x G.67) $\times($ G.72 $\times$ Del. $)] \times$ (G.89 $\times$ G.86) $\}$ with the high distance could be used as a parent in the breeding programs.

Keywords: Heritability, Gosssypium barbadense, L., Promising lines, cotton yield traits, Stability statistic analysis, $G \times E$ interaction, genetic distance 


\section{INTRODUCTION}

The progress of any breeding programme depends on available genetic variation to produce new superior cotton varieties that can replace the existing ones. Also the choice of high genetic diversity parents which have a high level of stability in the beginning of the breeding programs is very important step for the success of such programs. So, breeding genotypes with wide adaptability and high genetic diversity is very important for cotton breeders. El- Feki et al , (2005) studied the genetic diversity for advanced promising strains by using of hierarchical clustering and found that the studied genotypes were divided into two clusters which were jointed at the distance level 16.49.El- Hoseiny(2013) showed that boll weight and earliness were the main characters responsible for yield performance, while the traits fiber length and fiber strength were the main components for yarn strength. Campdell and Jones (2005) indicated that genotypes stability for trait performance is a direct measure of the presence effect of genotypes. Genotype $\boldsymbol{x}$ environment interaction is the major concern to plant breeders for developing and improving cultivars. The obscure impact of the genotype environment interaction (GEI) on the relative performance and stable genotype across environment is important and forms challenging difficultly to the breeder in developing superior cultivar adaptation, Eberhart and Russell (1966) .Yield is influenced mostly by environments, genotypes, and Genotype $\boldsymbol{x}$ environment interaction. Merdith et al, (2012) the yielding ability of genotypes is a result of its interactions with the environmental conditions and the contribution of the genes (level of expression) regulating the traits among environments. Khan et al, (2007) observed that successful evaluation of stable genotype which could be used for general cultivation depends on information on genotype $\boldsymbol{x}$ environment interaction (GEI). Several techniques have been proposed to characterize the stability of yield performance when the genotypes are tested at a number of environments. Tai (1971) suggested partitioning the genotype $\mathrm{x}$ environment interaction into two components namely: a statistic that measures the linear response to environmental effect and $\lambda$ that measures the deviation from linear response in terms of magnitude of error variance. Badr (2003) found that average genotype stability degrees were recorded for seed cotton yield for Giza 85 and boll weight for G.89. Rahoumah et al, (2008) found that the nine genotypes No. 1, 2, 3, 4, 6, 15, 17, 19 and the promising cross (Giza 89xGiza 86) exhibited high average level of stability, also found that the genotype No.1 and 16 revealed the lower genetic distance, while the genotypes No. 13 and 14 showed the highly genetic distance. Abd El-Moghny and Max (2015) indicated that the a variety or genotype could be considered of more adaptability or stable if it had high mean yield but alow degree of fluctuation in yielding ability when grown in diverse environments. 
The main objective of the present study is to evaluate strains of five crosses at six different locations and to estimate genetic diversity and mean performance of each genotype for yield components traits by determine genotypic and phenotypic stability level for each genotype over environments.

\section{MATERIALS AND METHODS}

Twenty four cotton genotypes belonging to Gossypium barbadense L. were tested throught the advanced strain test Trail B of the Cotton Breeding Research Section, Cotton Research Institute Agricultural Research Center Giza Egypt. The genotypes included twenty one strains descended from five crosses, the promising cross ([(G.89 x Karsh.) x G.86] xG.94 and the two commercial varieties (G.94 and G86). The genotypes were cultivated at six locations in Lower Egypt i.e. Kafr ElShekh, El-Dakahlia, El-Monofeia, El-Sharkia, El-Gharbia and El Behera during 2016 season. These locations represented the most important production area for long staple varieties. Origin and pedigree of these genotypes are shown in Table1.

Table 1. Origin and pedigree of the studied cotton genotypes (Trial B)

\begin{tabular}{|c|c|c|c|}
\hline \multicolumn{2}{|c|}{ No. Genotypes } & Parent & 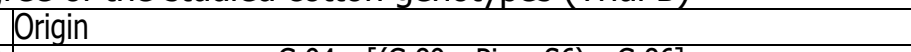 \\
\hline 1 & F6 549/15 & F5 503/13 & G.94 x [(G.89 x Pima S6) X G.86] \\
\hline 2 & F8 587/15 & $\begin{array}{ll}F 7582 \\
/ 13\end{array}$ & \multirow{3}{*}{ (G.89 x Pima S6 ) x Suvin } \\
\hline 3 & F8 $598 / 15$ & 77590 & \\
\hline 4 & F8 $599 / 15$ & F7 & \\
\hline 5 & F8 $600 / 15$ & $\begin{array}{l}77601 \\
/ 13\end{array}$ & \multirow{8}{*}{$($ G. $89 \times$ Pima S6) $\times\{[($ Bah. $105 \times$ x G.67) $\times($ G.72 $\times$ Del..$)]$ X (G.89 x86) $\}$} \\
\hline 6 & F8 602/15 & F7 "I & \\
\hline 7 & F8 $604 / 15$ & $\begin{array}{l}F 7602 \\
/ 13\end{array}$ & \\
\hline 8 & F8 $609 / 15$ & $\begin{array}{l}F 7607 \\
113\end{array}$ & \\
\hline 9 & F8 $610 / 15$ & F7" & \\
\hline 10 & F8 $615 / 15$ & $\begin{array}{l}\text { F } 7611 \\
/ 13\end{array}$ & \\
\hline 11 & F8 $620 / 15$ & F7 612 & \\
\hline 12 & F8 $621 / 15$ & F7 & \\
\hline 13 & F9 $629 / 15$ & $\begin{array}{l}\text { F8 } 614 \\
/ 13\end{array}$ & \multirow{3}{*}{$(\mathrm{G} .85 \times \mathrm{G} .86) \times[(G .83 \times \mathrm{G} .80) \times \mathrm{G} .89]$} \\
\hline 14 & F9 $632 / 15$ & F8 615 & \\
\hline 15 & F9 $635 / 15$ & 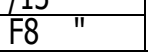 & \\
\hline 16 & F10 $658 / 15$ & $\begin{array}{l}\text { F9 } 674 \\
/ 13\end{array}$ & \multirow{4}{*}{ G.85 x (G.89 x G.86) } \\
\hline 17 & F10 $660 / 15$ & $\begin{array}{l}\text { F9 } 675 \\
/ 13\end{array}$ & \\
\hline \begin{tabular}{l|}
18 \\
19 \\
20
\end{tabular} & \begin{tabular}{|l|} 
F10 $661 / 15$ \\
F10 $663 / 15$ \\
F10 $664 / 15$
\end{tabular} & $\begin{array}{l}\text { F9 " } \\
\text { F9 } 677 / 13 \\
\text { F9 " }\end{array}$ & \\
\hline 21 & F10 $665 / 15$ & F9 $678 / 13$ & \\
\hline 22 & \multicolumn{2}{|c|}{$\left[\begin{array}{c}{[(G .89 x \text { Karsh. }) \times G .86]} \\
\times G .94\end{array}\right.$} & \\
\hline 23 & \multirow{2}{*}{\multicolumn{2}{|c|}{\begin{tabular}{|l|} 
Giza 94 \\
Giza 86 \\
\end{tabular}}} & \\
\hline 24 & & & \\
\hline
\end{tabular}

(Kantar of seed cotton yield $=157,5 \mathrm{Kg}$, Kentar of lint yield $=50 \mathrm{Kg}$ and Faddan $=4200 \mathrm{~m}^{2}$ )

(Bah. = Bahteem , Del.= Delecro ) 
Experimental design in all locations was randomized complete blocks design with six replications, each plot consisted of five rows. The row was four meters long, $70 \mathrm{~cm}$ apart, and $25 \mathrm{~cm}$ between hills. Each hill was thinned to two plants per hill Standard cultural practices were applied as recommended for cotton crop.

The middle three rows of each plot were hand harvested twice to determine seed cotton yield per plot in kentar/feddan (S.C.Y) and lint cotton yield (L.C.Y) in kentar/ Feddan

Random sample of 50 bolls picked from the outer two rows was used to obtain average boll weight (B.W), earliness index (E.I) expressed as (yield of the first pick /total of seed cotton yield) $\times 100$. Lint percentage (L. \%): calculated from the formula: (weight of lint cotton yield in sample/weight of seed cotton yield) $x 100$. Fiber measurements included: Fiber fineness (F.F): measured by Micronaire apparatus in Micronaire units (Mic). Fiber strength (F.S): expressed as g/tex, fiber length (U.H.M): upper half mean in mm. measured by high volume instrument (H.V.I). Color as degree of yellowness (+b): Measured by (H.V.I), Yarn measurements included: Yarn strength (Y.S.): expressed as Lea product of "Lea strength x Yarn Count" (for 60 s carded) yarn with 3.6 twist multiplier measured by the Good Brand Lea strength tester. All fiber properties tests were performed in the Laboratory of the Cotton Technology Research Section, Cotton Research Institute, Agricultural Research Center, Giza, according to ASTM (1998).

Table 2. Form of the combined analysis of variances and expectations of mean squares for all genotypes over environments

\begin{tabular}{|l|c|c|c|}
\hline \multicolumn{1}{|c|}{ S.O.V. } & d.f & M.S & E.M.S \\
\hline Environments(E) & $\mathrm{L}-1$ & & \\
Replications/ L & $\mathrm{L}(\mathrm{r}-1)$ & & \\
Genotypes & $\mathrm{g}-1$ & $\mathrm{M} 3$ & $\sigma^{2} \mathrm{e}+r \sigma^{2} \mathrm{~g} \mathrm{~L}+\mathrm{rL} \sigma^{2} \mathrm{~g}$ \\
Genotypes x E & $(\mathrm{g}-1)(\mathrm{L}-1)$ & $\mathrm{M} 2$ & $\sigma^{2} \mathrm{e}+\mathrm{r} \sigma^{2} \mathrm{~g} \mathrm{~L}$ \\
Error & $\mathrm{L}(\mathrm{g}-1)(\mathrm{r}-1)$ & $\mathrm{M} 1$ & $\sigma^{2} \mathrm{e}$ \\
\hline
\end{tabular}

Where:

$\mathrm{E}, \mathrm{r}$ and $\mathrm{g}$ : environments, replications and genotypes, respectively.

M1, M2 and M3: are errors, genotypes by environments interactions and genotypic variances, respectively.

Heritability estimated, in broad sense (h2bs \%) was calculated by using the formula:-

$\mathrm{h}^{2} \mathrm{~b} \% \%=(62 \mathrm{~g} /(62 \mathrm{ge}+62 \mathrm{e})) \times 100$

Where: $\sigma^{2} g$ : genotypes variance component.

$\sigma^{2}$ ge: variance component due to genotypes $x$ environment.

$\sigma^{2} \mathrm{e}$ : error variance component. 
Combining analyses of variance was done using the data of each location to create the means data for the phenotypic and genotypic stability analyses. Analysis of variance was carried out for the individual combined locations with fixed genotypes effects and random replicate of environmental effects according to Le Clerge et al (1962) and Snedecor (1965).

The genotypic stability analysis was done according to the method described by Tai (1971). Stability parameters $\left(a_{i}\right)$ and $\left(\lambda_{i}\right)$ were estimated for each variety separately. Parameter Alfa (a) measures the linear response to environmental effects and Lambda $(\lambda)$ measures the deviation from linear response in terms of magnitude of error variance. The perfectly stable genotype is that in which value $(a=-1, \lambda=1)$.

The phenotypic stability analysis was done according to the method of Eberhart and Russell(1966),suggested that optimal yield stability measured through regression approaches would be represented by a cultivar with high mean yield, close to unity bi value, or responsive to favorable environmental conditions, and with deviations from regression $\mathrm{S}^{2} \mathrm{~d}$ as low as possible.

Estimating of genetic distance, cluster analysis were presented as dendrogram constructed on Euclidean distance as outlined by Anderberg (1973) and developed by Hair et al (1987).

\section{RESULTS AND DISCUSSION}

Study of the breeding behavior of genotypes grown under different environments to evaluate the genotypes stability in different locations is very important. The combining analysis of variance for twenty four cotton genotypes evaluated over six locations is presented in Table (3). Data in Table (3) indicated highly significant different among locations for studied traits indicated that theses locations were diverse. Also genotypes had highly significant differences except for boll weight which was significant. This suggested that these genotypes differed considerably with respect to yield productivity. Genotypes $\mathrm{x}$ location interaction had highly significant different for studied traits indicated that the response of these genotypes to the environments was not similar and reduction of selection progress could be affected by high genotypes $x$ location interaction and allowing to further stability analysis. This agree with the results obtained by El Hoseiny ( 2011) and Abd El-Moghny and Max (2015). 
Table 3.Combined analysis of variances for all genotypes for studied traits evaluated over six location

\begin{tabular}{|l|c|c|c|c|}
\hline S .O. V & d.f & B.W & S.C.Y & L.Y \\
\hline Location & 5 & $22.484 * *$ & $98886238.186 * *$ & $15688689.929 * *$ \\
\hline Replications & 30 & 0.1511 & 2132756.661 & 346025.313 \\
\hline Genotypes & 23 & $0.519 *$ & $836967.879 * *$ & $206935.834 * *$ \\
\hline Genotypes*Location & 115 & $0.275^{* *}$ & $288313.225 * *$ & $54340.319 * *$ \\
\hline Error & 690 & 0.1173 & 239258.454 & 39034.7 \\
\hline
\end{tabular}

The means performance of studied traits for all genotypes over six locations are presented in Table (4). Data in Table (4) showed that most of genotypes surpassed the check variety Giza 86 significantly in all studied traits except for earliness index (E.I) and Yarn strength (Y.S.). Mean performance for boll weight ranged from (2.98 to $3.68 \mathrm{~g}$ ) for genotype No.21,1, seed cotton yield ranged from (8.83 to 11.24 ken/fed) for genotype No.24,8, lint cotton yield ranged from (10.78 to 14.44 ken/fed) for genotype No.24,8, Lint percentage (L. \%) ranged from (38.6 to42.5) for genotype No.24,1, Earliness index ( $E$ \%) ranged from (47.6 to 67.6 ) for genotype No.24, 10, Micronaire reading were from (3.8 to 4.3) for genotype No.2, 8 , fiber strength ranged from (40.3 - 46.9)g/tex. for genotype No.2,13, fiber length(F.L.) ranged from (30.5 to 32.6 ) mm, for genotype No.17,6, and Yarn strength ranged from(2148 to 2459) for genotype No.8,24.The highest seed and lint cotton yield $(11.14,14.44)$ ken/fed., was achieved by genotype No.8 $F_{6} 609 / 2015$ which belong to the cross (G.89 $\times$ Pima S6) $\times\{[($ Bah.105 $\times$ G.67) $\times($ G.72 $\times$ Del. $)] \mathrm{X}$ ( $G .89 \times 86)\}$ with increase above the check variety $G .86$ by $(2.31,3.46)$ ken/fed., for seed and lint cotton yield, respectively. While genotypes No.1, F6 549/15, 4, F8 599 /15, 7, F8 604 /15, 8, F8 609 /15, 9, F8 610/15 and 20, F10 664 /14 had higher boll weight, seed cotton yield and lint yield than over all mean.

Two measures of phenotypic stability i.e., regression coefficient and sum of square deviation from regression were computed for twenty four genotypes for boll weight, seed cotton yield and lint yield. According to the definition of Eberhart and Russell(1966), a stable preferred cultivar would have approximately bi $=1, \mathrm{~S}^{2} \mathrm{~d}$ $=0.0$ and a high mean of performance. Data in Tables $(5,6$ and 7$)$ showed that regression coefficient (bi) value for boll weight ranged from 0.224 for genotype No. 14 to 2.120 for genotype No. 14, for seed cotton yield ranged from 0.782 for genotype No.2 to 1.284 for genotype No.5, and for lint cotton yield ranged from 0.704 for genotype No. 2 to 1.33 for genotype No. 5 These variations in (bi) values suggested that these cotton genotypes responded differently to the different environments. \{The results in Table (5, 6 and 7) showed that genotypes No.1,18 for boll weight, No.9 for seed cotton yield and No.7 for lint cotton yield had regression coefficient close to unity and deviation from regression near zero. These genotypes 
could be successfully used for general cultivation, making it widely adapted or stable genotypes. However genotypes No.1,8,10and11 for boll weight, No. $1,4,7,8,9,10,20,22$ and 23 for seed cotton yield and No.1,3,4,7,8,9,10,20,22and23 for lint cotton yield had higher mean performance and regression coefficient close to unity, while deviation from regression differ from zero. These genotypes are considered as sensitive to environmental variations and would be suggested for cultivation under favorable conditions. Also some genotypes had regression coefficient low or high unity and deviation from regression were high representing so, unpredictable portion. Similar results were reported by Dewdar (2013) and Gibely et al,(2015).

Table 4. Mean performance of the twenty four cotton genotypes for yield and its components and fiber properties evaluated across six locations

\begin{tabular}{|c|c|c|c|c|c|c|c|c|c|c|}
\hline Genotypes & B.W & S.C.Y & L.C.Y & L\% & E.I & Mic. & g/tex & F.L & +b & Y.stre. \\
\hline 1 & 3.68 & 10.75 & 14.38 & 42.5 & 56.3 & 4.1 & 41.5 & 32.3 & 8.3 & 2448 \\
\hline 2 & 3.52 & 9.84 & 12.43 & 40.1 & 64.5 & 3.8 & 40.8 & 32.0 & 9.3 & 2407 \\
\hline 3 & 3.50 & 10.13 & 13.17 & 41.4 & 64.7 & 4.1 & 41.2 & 31.4 & 8.5 & 2302 \\
\hline 4 & 3.47 & 10.41 & 13.11 & 40.0 & 63.1 & 4.1 & 43.8 & 31.8 & 8.9 & 2255 \\
\hline 5 & 3.61 & 9.87 & 12.57 & 40.3 & 61.0 & 4.1 & 42.6 & 32.4 & 8.6 & 2293 \\
\hline 6 & 3.63 & 10.15 & 12.86 & 40.2 & 55.7 & 4.0 & 42.7 & 32.6 & 8.5 & 2268 \\
\hline 7 & 3.34 & 10.63 & 13.40 & 40.2 & 57.1 & 4.1 & 42.8 & 31.3 & 8.9 & 2353 \\
\hline 8 & 3.36 & 11.24 & 14.44 & 40.6 & 65.2 & 4.3 & 40.9 & 32.2 & 8.9 & 2148 \\
\hline 9 & 3.51 & 10.58 & 13.71 & 41.1 & 63.8 & 4.1 & 42.0 & 31.5 & 8.7 & 2282 \\
\hline 10 & 3.46 & 10.44 & 13.22 & 40.2 & 67.6 & 4.0 & 41.7 & 31.7 & 8.5 & 2217 \\
\hline 11 & 3.43 & 10.01 & 12.67 & 40.2 & 64.9 & 3.9 & 43.4 & 32.1 & 8.9 & 2365 \\
\hline 12 & 3.12 & 10.07 & 12.73 & 40.0 & 63.2 & 4.0 & 43.4 & 32.6 & 8.6 & 2357 \\
\hline 13 & 3.50 & 9.97 & 12.50 & 40.1 & 48.3 & 4.0 & 46.2 & 31.7 & 8.9 & 2369 \\
\hline 14 & 3.23 & 9.73 & 12.53 & 41.1 & 46.7 & 4.0 & 44.4 & 31.8 & 9.2 & 2436 \\
\hline 15 & 3.24 & 9.94 & 12.45 & 39.7 & 51.9 & 4.2 & 45.6 & 31.4 & 8.8 & 2376 \\
\hline 16 & 3.08 & 10.15 & 12.71 & 39.8 & 66.0 & 3.9 & 43.9 & 30.9 & 9.1 & 2377 \\
\hline 17 & 3.16 & 10.08 & 12.68 & 40.1 & 61.1 & 4.2 & 43.5 & 30.5 & 8.9 & 2419 \\
\hline 18 & 3.14 & 10.10 & 12.54 & 39.4 & 65.0 & 4.0 & 44.9 & 30.7 & 8.8 & 2454 \\
\hline 19 & 3.11 & 10.13 & 12.64 & 39.7 & 61.1 & 4.0 & 45.7 & 31.2 & 9.2 & 2265 \\
\hline 20 & 3.34 & 10.38 & 13.20 & 40.3 & 63.9 & 4.0 & 44.2 & 30.9 & 9.2 & 2429 \\
\hline 21 & 2.98 & 9.87 & 12.18 & 39.3 & 65.0 & 4.2 & 45.2 & 31.0 & 9.1 & 2300 \\
\hline 22 & 3.10 & 11.20 & 14.20 & 40.2 & 63.9 & 3.9 & 43.4 & 32.6 & 9.1 & 2355 \\
\hline 23 & 3.23 & 10.51 & 13.24 & 39.9 & 59.6 & 3.9 & 42.4 & 33.1 & 8.7 & 2349 \\
\hline 24 & 3.13 & 8.83 & 10.78 & 38.6 & 47.6 & 4.1 & 43.9 & 32.1 & 8.8 & 2459 \\
\hline mean & 3.33 & 10.20 & 12.92 & 40.2 & 60.3 & 4.0 & 43.3 & 31.7 & 8.8 & 2345 \\
\hline S.E & 0.114 & 0.732 & 0.931 & & & & & & & \\
\hline LSD 5 & 0.172 & 1.435 & 1.825 & & & & & & & \\
\hline $1 \%$ & 0.226 & 1.886 & 2.399 & & & & & & & \\
\hline
\end{tabular}

Genotypic stability parameters ( $a$ and $\lambda$ ) were calculated according to Tai (1971) method. Perfectly stable genotype will not change its performance from one environment to another. This is equivalent to stating that ( $a=-1$ and $\lambda=1$ ) while genotype that has average stable might have an estimates of $(a=0.0$ and $\lambda=1)$.The estimates of genotypic stability parameters presented in Table $(5,6,7)$ illustrated the 
( $a$ and $\lambda$ ) distribution of twenty four genotypes for boll weight seed and lint cotton yield, respectively.

Considering boll weight, Table (5) and Fig.1 showed that the genotypes No.1, 2, 5, 12, 13, 18, 21, 22(promising cross) and 23(G.94) had average level of stability, genotype No. 3 had average level of stability (at $p=0.90$ and $p=0.95$ ) while genotypes No. $8,7,14$ had high level of stability (at $p=0.99$ ) and average level of stability (at $p=0.90$ and $p=0.95$ ). The genotypes No. 1 was stable and had the highest boll weight .The rest were considered unstable genotypes.

Regarding seed cotton yield results in Table (6) and Fig. 2 showed that the genotypes No. $1,3,6,7,9,10,12,13,14,15,18,19,20,21,23$ and 24 had average level of stability. Moreover, genotypes No.1, 7, 9, 10, 20 and 23 belonging to the crosses G.94 x [(G.89 x Pima S6) x G.86], (G.89 x Pima S6) x \{[(Bah.105 x G.67) x (G.72 x Del.) $X$ (G.89 × G.86)\}, G.85 × (G.89 × G.86), respectively and G.94 were stable and surpassed overall mean, also increased significantly compared with G. 86 . The increases were ranged from (1.55 - 1.92) ken / fed. Considering lint cotton yield results in Table (7) and Fig. 3 showed that the genotypes No.3,6,7,8,9,10,12,14,15,16,19,20,21,23and 24 achieved average level of stability, while genotype No.5 had average level of stability (at $p=0.90$ andp-0.95) .Genotypes No.3,6,7,8,9,10,12,16,19, and 20 belonging to the crosses (G.89 x Pima S6) $x$ Suvin, G.89 x Pima S6) $\times\{[($ Bah.105 x G.67) $\times($ G.72 $\times$ Del. $)] \times(G .89 \times$ G.86) and G.85 x $(\mathrm{G} .89 \times \mathrm{G} .86)$, $)$, respectively and the check variety G.94 were stable, and increased significantly compared with G.86. The increases were ranged from (1.40 - 3.66) ken / fed. The highest lint cotton yield (14.44) kentar/ faddan was achieved by the genotype No. (8) F8 609 /15 belongs to the cross (G.89 x Pima S6) $\times\{[($ Bah.105 $\times$ G.67) $\times($ G.72 $\times$ Del. $)] \times(G .89 \times$ G.86) $\}$ which surpassed the control variety G.86 by (3.66 ken/fad. These results were agreed with those obtained by El-Helow et al, (2002) and Badr (2003).) and Ali et al (2012), Concerning heritability value estimates data in Tables $(5,6,7)$ revealed that heritability values in broad sense were high (over $50 \%$ ) for boll weight, seed cotton yield and lint cotton yield, respectively indicating that the genetic variability is low so phenotypic selection for these genotypes could be highly effective. Contrasting results were found by Iqbal et al (2011) who revealed that the estimates of heritability for boll weight, seed cotton yield and lint cotton yield were of high value. Gibely et al, (2015) found high heritability values for seed and lint cotton yield, while moderate value was obtained for boll weight. Saleh (2016) found high heritability estimates in broad sense for boll weight, seed and lint cotton yield.

Hierarchical clustering was applied to determine the relative similarity and diversity within the tested germplasm. Table (8) and the dendrogram in Fig. (4), 
showed that the studied genotypes were divided into two clusters at level of similarity $77.8 \%$ with distance $96.07 \%$. The first represented by genotype No. 8 and the second by node22. This result indicated that genotype No.8 differs than other genotypes. The node22 separated at level $84.7 \%$ and distance level 47.6 to node 21 and node22, node 21 divided into two nodes, the first represented by node18 and the other represented by genotype No10 at level of similarity $87.7 \%$ with distance 38.33 and node18 contain the 7 genotypes which were distributed in small groups according to small distance. These genotypes were number 3,21,5,9,4,6 and 19. The node No. 20 were divided into two nodes, node19 and node15 which were separated to number of groups. These groups divided at small distance. The first node contain the genotypes number $1,18,14,2,17,20$ and 24(G.86), the second of them were contain the genotypes No. 7,12,11,16,13,15,23(G.94) and 22 ( the variety G.94) and 22 ( the promising cross [ ( G.89 x Karsh.) x G.86] x G.94). Meanwhile the largest distance was observed between all genotypes and No.8 (F8615/14) with distance (69.074) and similarity level $(77.83 \%)$. While the narrow distance was observed between the genotype No.12 ( $\mathrm{F}_{8}$ 621/14) and the promising cross [(G.89 x Karsh.) x G.86] x G.94 with distance (3.411)and similarity level (98.91\%) Based on this classification and the characters for all genotypes from the dendrogram on Fig. 4 can conclude that the promising cross [( G.89 x Karsh.) x G.86] x G.94 can replace G.94, while genotypes No. 1,14 , and18 can replace G.86 and the genotype No. 8 is superior than other genotypes regarding to studied characters and is considered one of the promising genotypes which need further investigation. Similar results were obtained by El- Feki et al (2005), Rahouma et al (2008) El-Hoseiny (2013) and Max (2015).

Generally, the cotton breeder should choose the genotypes which have the highest stability at various environments, high yield and fiber quality performance to be used as commercial varieties. Also should be choose the parents with high genetic distance to begin the breeding program to increase the percent of segregation and producing stable high yielding genotypes. From the previous results it could be concluded that genotypes No.12, 21 and 23(check variety G.94) met the assumption of the stable genotype as describe by Tai (1971), and high yield potential. These genotypes possessed high mean performances and stability for the studied traits. These genotypes may be recommended to substitute the commercial varieties. According to the previous results the cross [(G.89 x Karsh.) x G.86] xG.94 could be good substitute to the variety G.94, genotypes No.14 F8632/2015 descending from the cross (G.89 xG.86) x [(G.83 x80) x G.89], No.18 F F $_{1} 0661 / 2015$ descending from the cross G.85 x(G.89x G.86) and No.1 descending from the cross G.94 x [(G.89 x Pima S6) $x$ G.86] could be good substitute to the variety G.86. Therefore the genotype No. 
$8 \mathrm{~F}_{8}$ 609/2015 descending from the cross (G.89 x Pima S6) $x\{[($ Bah.105 $\times$ G.67) $\times$ (G.72 x Del.)] X (G.89 xG.86)\} could be used as a parent in the beginning of the breeding program.

Table 5. Estimates of stability parameters for twenty four genotypes studied over six locations for boll weight(g) in 2016 season.

\begin{tabular}{|c|c|c|c|c|c|}
\hline \multirow{3}{*}{ Genotypes No. } & \multirow{3}{*}{ Mean } & \multirow{2}{*}{\multicolumn{2}{|c|}{ Phenotypic stability }} & \multicolumn{2}{|c|}{ Genotypic stability } \\
\hline & & & & \multirow{2}{*}{$a_{i}$} & \multirow{2}{*}{$\lambda_{\mathrm{i}}$} \\
\hline & & $b_{i}$ & $S^{2} d_{i}$ & & \\
\hline 1 & 3.68 & 0.874 & -1.014 & -0.248 & 0.594 \\
\hline 2 & 3.52 & 2.053 & -1.455 & 0.495 & 1.900 \\
\hline 3 & 3.50 & 2.120 & -1.568 & 0.459 & 1.018 \\
\hline 4 & 3.47 & 1.364 & -2.076 & 0.115 & 0.024 \\
\hline 5 & 3.61 & 1.822 & -1.507 & 0.398 & 1.200 \\
\hline 6 & 3.63 & 1.503 & -1.917 & 0.173 & 0.081 \\
\hline 7 & 3.34 & 0.564 & -1.227 & -0.409 & 0.798 \\
\hline 8 & 3.36 & 0.732 & -1.181 & -0.322 & 0.673 \\
\hline 9 & 3.51 & 1.433 & -2.049 & 0.254 & 0.254 \\
\hline 10 & 3.46 & 1.281 & -2.154 & 0.143 & 0.200 \\
\hline 11 & 3.43 & 0.932 & -2.124 & -0.036 & 0.300 \\
\hline 12 & 3.12 & 0.950 & -1.084 & -0.143 & 0.916 \\
\hline 13 & 3.50 & 0.572 & -1.846 & -0.282 & 0.700 \\
\hline 14 & 3.23 & 0.224 & -1.660 & -0.503 & 1.049 \\
\hline 15 & 3.24 & 0.463 & -2.006 & -0.319 & 0.438 \\
\hline 16 & 3.08 & 0.961 & -1.988 & 0.031 & 0.062 \\
\hline 17 & 3.16 & 0.982 & -1.991 & 0.060 & 0.350 \\
\hline 18 & 3.14 & 1.504 & -0.796 & 0.426 & 1.400 \\
\hline 19 & 3.11 & 0.513 & -2.103 & -0.297 & 0.246 \\
\hline 20 & 3.34 & 0.853 & -1.699 & 0.008 & 0.187 \\
\hline 21 & 2.98 & 1.290 & -0.808 & 0.319 & 0.945 \\
\hline 22 & 3.10 & 0.432 & -1.687 & -0.119 & 0.600 \\
\hline 23 & 3.23 & 0.490 & -1.955 & -0.246 & 1.000 \\
\hline 24 & 3.13 & 0.531 & -1.152 & 0.043 & 0.400 \\
\hline overall Mean & 3.3 & & & & \\
\hline L.S.D 0.05 & 0.172 & & & & \\
\hline L.S.D 0.01 & 0.226 & & & & \\
\hline$h^{2} b$ & 72.46 & & & & \\
\hline
\end{tabular}


Table 6. Estimates of stability parameters for twenty four genotypes studied over six locations for seed cotton yield (ken/fed) in 2016 season.

\begin{tabular}{|c|c|c|c|c|c|}
\hline \multirow{3}{*}{ Genotypes No. } & \multirow{3}{*}{ Mean } & \multirow{2}{*}{\multicolumn{2}{|c|}{ Phenotypic stability }} & \multicolumn{2}{|c|}{ Genotypic stability } \\
\hline & & & & \multirow{2}{*}{$a_{i}$} & \multirow{2}{*}{$\lambda_{\mathrm{i}}$} \\
\hline & & $b_{i}$ & $S^{2} d_{i}$ & & \\
\hline 1 & 10.75 & 1.194 & 9.955 & 0.195 & 1.765 \\
\hline 2 & 9.84 & 0.782 & -13.832 & -0.222 & 0.388 \\
\hline 3 & 10.13 & 0.893 & -0.610 & -0.115 & 1.165 \\
\hline 4 & 10.41 & 0.840 & 22.377 & -0.166 & 2.485 \\
\hline 5 & 9.87 & 1.284 & -12.758 & 0.283 & 0.438 \\
\hline 6 & 10.15 & 1.011 & -9.831 & 0.008 & 1.000 \\
\hline 7 & 10.53 & 1.083 & -8.162 & 0.082 & 0.600 \\
\hline 8 & 11.24 & 1.124 & 18.945 & 0.122 & 2.292 \\
\hline 9 & 10.58 & 0.992 & -0.739 & -0.013 & 1.162 \\
\hline 10 & 10.44 & 0.910 & -10.478 & -0.096 & 1.500 \\
\hline 11 & 10.01 & 1.074 & -14.495 & 0.070 & 0.367 \\
\hline 12 & 10.07 & 1.133 & -11.224 & 0.132 & 0.550 \\
\hline 13 & 9.97 & 1.082 & -7.389 & 0.081 & 0.776 \\
\hline 14 & 9.73 & 0.874 & 0.461 & -0.134 & 1.225 \\
\hline 15 & 9.94 & 1.004 & -9.816 & -0.003 & 1.500 \\
\hline 16 & 10.15 & 0.983 & -13.895 & -0.019 & 0.403 \\
\hline 17 & 10.08 & 1.032 & -17.094 & 0.033 & 0.218 \\
\hline 18 & 10.10 & 0.941 & 11.579 & -0.061 & 1.871 \\
\hline 19 & 10.13 & 1.004 & 7.735 & 0.000 & 1.651 \\
\hline 20 & 10.38 & 1.032 & -7.614 & 0.030 & 0.765 \\
\hline 21 & 9.87 & 0.951 & -0.661 & -0.053 & 1.166 \\
\hline 22 & 11.20 & 1.002 & -16.764 & 0.000 & 0.237 \\
\hline 23 & 10.51 & 0.924 & -10.270 & -0.078 & 0.750 \\
\hline 24 & 8.83 & 0.923 & 3.170 & -0.078 & 1.385 \\
\hline overall Mean & 10.2 & & & & \\
\hline L.S.D 0.01 & 1.886 & & & & \\
\hline L.S.D 0.05 & 1.435 & & & & \\
\hline$h^{2} b$ & 71.41 & & & & \\
\hline
\end{tabular}


Table 7. Estimates of stability parameters for twenty four genotype studied over six locations for lint cotton yield ( ken/fed) in 2016 season

\begin{tabular}{|c|c|c|c|c|c|}
\hline \multirow{3}{*}{ Genotypes No. } & \multirow{3}{*}{ Mean } & \multirow{2}{*}{\multicolumn{2}{|c|}{ Phenotypic stability }} & \multicolumn{2}{|c|}{ Genotypic stability } \\
\hline & & & & \multirow{2}{*}{$a_{i}$} & \multirow{2}{*}{$\lambda_{\mathrm{i}}$} \\
\hline & & $b_{i}$ & $S^{2} d_{i}$ & & \\
\hline 1 & 14.38 & 1.123 & 16.657 & 0.257 & 2.287 \\
\hline 2 & 12.43 & 0.704 & -14.852 & -0.201 & 0.367 \\
\hline 3 & 13.17 & 0.971 & 20.031 & -0.151 & 0.957 \\
\hline 4 & 13.11 & 0.823 & 21.793 & -0.189 & 2.838 \\
\hline 5 & 12.57 & 1.334 & -7.607 & 0.360 & 0.676 \\
\hline 6 & 12.86 & 1.023 & -5.501 & 0.026 & 0.810 \\
\hline 7 & 13.40 & 1.032 & 0.299 & -0.013 & 1.320 \\
\hline 8 & 14.44 & 1.172 & 6.939 & 0.149 & 1.735 \\
\hline 9 & 13.71 & 0.994 & -15.289 & 0.056 & 1.054 \\
\hline 10 & 13.22 & 0.983 & -17.257 & -0.057 & 0.588 \\
\hline 11 & 12.67 & 1.170 & -25.985 & 0.078 & 0.308 \\
\hline 12 & 12.73 & 1.212 & 4.655 & 0.194 & 1.071 \\
\hline 13 & 12.50 & 0.863 & -32.230 & 0.028 & 0.425 \\
\hline 14 & 12.53 & 0.954 & -13.466 & -0.157 & 0.676 \\
\hline 15 & 12.45 & 0.973 & -26.383 & 0.014 & 0.595 \\
\hline 16 & 12.71 & 0.932 & -10.406 & -0.055 & 0.717 \\
\hline 17 & 12.68 & 1.031 & -17.816 & -0.054 & 0.279 \\
\hline 18 & 12.54 & 0.972 & 23.052 & -0.086 & 2.556 \\
\hline 19 & 12.64 & 0.904 & 5.925 & -0.045 & 1.567 \\
\hline 20 & 13.20 & 1.113 & 3.681 & 0.070 & 1.230 \\
\hline 21 & 12.18 & 0.951 & -5.304 & -0.116 & 0.901 \\
\hline 22 & 14.20 & 0.993 & -22.428 & 0.000 & 0.338 \\
\hline 23 & 13.24 & 0.904 & -9.573 & -0.078 & 1.200 \\
\hline 24 & 10.78 & 0.932 & 14.505 & -0.078 & 1.696 \\
\hline overall Mean & 12.9 & & & & \\
\hline L.S.D 0.01 & 2.399 & & & & \\
\hline L.S.D 0.05 & 1.825 & & & & \\
\hline$h^{2} b$ & 81.14 & & & & \\
\hline
\end{tabular}




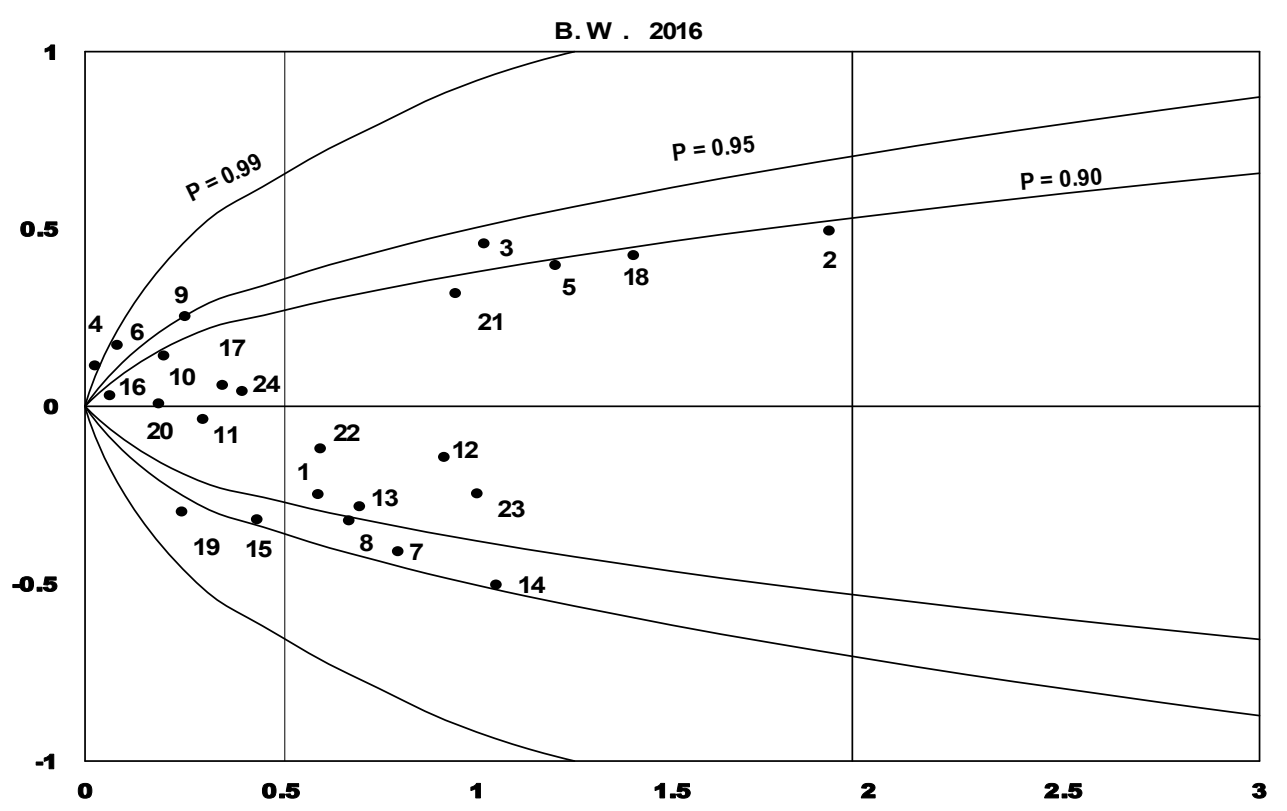

Fig. 1. Distribution of stability parameters for boll weight

\begin{tabular}{|c|c|c|c|}
\hline 1 F6 549/15 & 7 F8 $604 / 15$ & 13 F9 $629 / 15$ & $19 \mathrm{~F} 10663 / 15$ \\
\hline 2 F8 587/15 & 8 F8 $609 / 15$ & 14 F9 $632 / 15$ & 20 F10 $664 / 15$ \\
\hline 3 F8 $598 / 15$ & 9 F8 $610 / 15$ & 15 F9 $635 / 15$ & $21 \mathrm{~F} 10665 / 15$ \\
\hline 4 F8 $599 / 15$ & 10 F8 $615 / 15$ & 16 F10 $658 / 15$ & $22[(\mathrm{G} .89 \times$ Karsh. $) \times$ G.86] $\times \mathrm{G} .94$ \\
\hline 5 F8 $600 / 15$ & $11 \mathrm{~F} 8620 / 15$ & 17 F10 $660 / 15$ & 23 Giza 94 \\
\hline 6 F8 $602 / 15$ & 12 F8 $621 / 15$ & 18 F10 $661 / 15$ & 24 Giza 86 \\
\hline
\end{tabular}

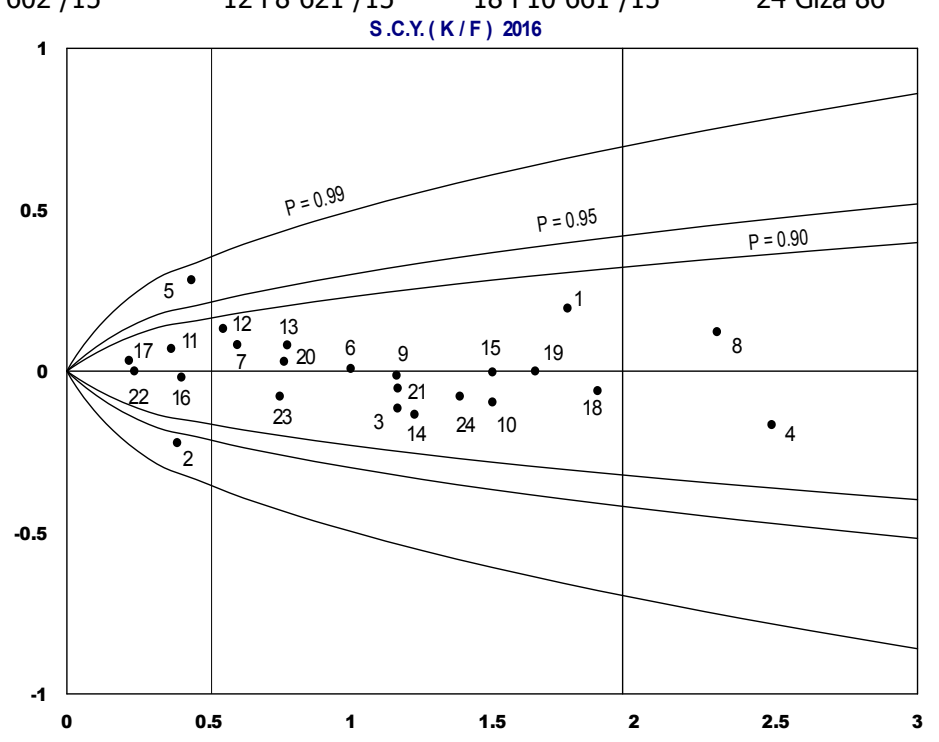

Fig. 2. Distribution of stability parameters for lint cotton yield

\begin{tabular}{|c|c|c|c|}
\hline 1 F6 549/15 & 7 F8 $604 / 15$ & 13 F9 $629 / 15$ & 19 F10 $663 / 15$ \\
\hline 2 F8 587/15 & 8 F8 $609 / 15$ & 14 F9 $632 / 15$ & 20 F10 $664 / 15$ \\
\hline 3 F8 $598 / 15$ & 9 F8 $610 / 15$ & 15 F9 $635 / 15$ & $21 \mathrm{~F} 10665 / 15$ \\
\hline 4 F8 $599 / 15$ & $10 \mathrm{~F} 8615 / 15$ & 16 F10 $658 / 15$ & $22[(G .89 \times$ Karsh. $) \times$ G.86] $] \times G .94$ \\
\hline 5 F8 $600 / 15$ & 11 F8 $620 / 15$ & 17 F10 $660 / 15$ & 23 Giza 94 \\
\hline F8 $602 / 15$ & 12 F8 $621 / 15$ & 18 F10 $661 / 15$ & 24 Giza 86 \\
\hline
\end{tabular}




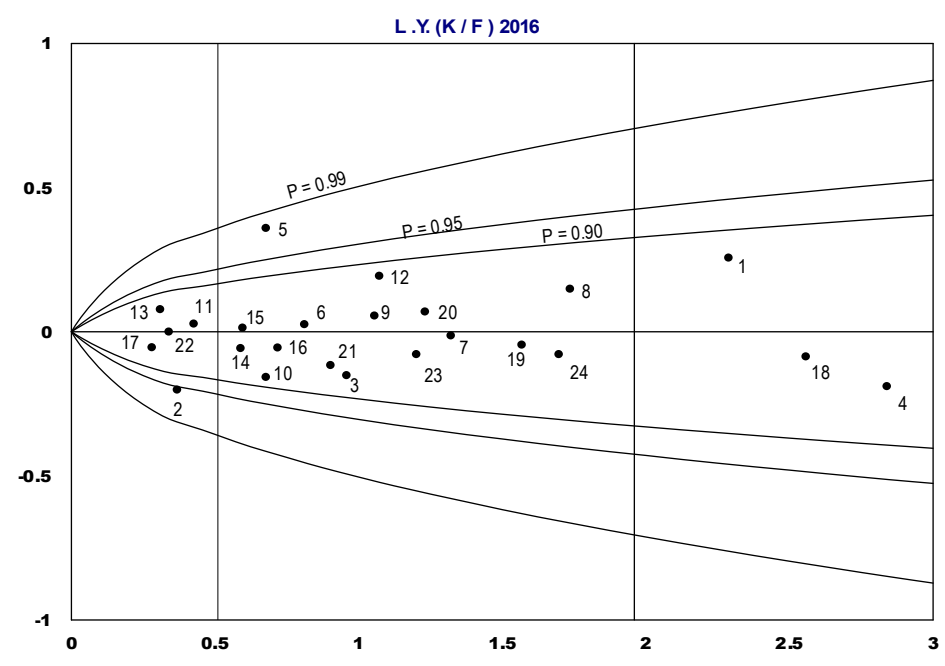

Fig. 3: Distribution of stability parameters for lint cotton yield

\begin{tabular}{|c|c|c|c|}
\hline 1 F6 549/15 & 7 F8 $604 / 15$ & 13 F9 $629 / 15$ & 19 F10 $663 / 15$ \\
\hline 2 F8 587/15 & 8 F8 $609 / 15$ & 14 F9 $632 / 15$ & 20 F10 $664 / 15$ \\
\hline 3 F8 $598 / 15$ & 9 F8 $610 / 15$ & 15 F9 $635 / 15$ & 21 F10 $665 / 15$ \\
\hline 4 F8 $599 / 15$ & 10 F8 $615 / 15$ & 16 F10 $658 / 15$ & 22 [(G.89 x Karsh.) x G.86] xG.94 \\
\hline 5 F8 $600 / 15$ & 11 F8 $620 / 15$ & 17 F10 $660 / 15$ & 23 Giza 94 \\
\hline $602 / 15$ & 12 F8 $621 / 15$ & 18 F10 $661 / 15$ & 24 Giza 86 \\
\hline
\end{tabular}

Table 8. Similarity and distance levels \% (dissimilarity) of studied genotypes according to hierarchical cluster analysis.

\begin{tabular}{|c|c|c|c|c|c|}
\hline \multirow{2}{*}{ Node } & \multicolumn{2}{|c|}{ Cluster joined } & \multirow{2}{*}{ Similarity\% } & Distance & No.of obs. \\
\cline { 2 - 3 } & Group1 & Group2 & & 3.411 & 2 \\
\hline 1 & 12 & 22 & 98.91 & 5.685 & 2 \\
\hline 2 & 3 & 21 & 98.18 & 7.355 & 2 \\
\hline 3 & 6 & 19 & 97.64 & 7.706 & 2 \\
\hline 4 & 7 & 23 & 97.53 & 7.792 & 4 \\
\hline 5 & Node4 & 12 & 97.5 & 8.274 & 5 \\
\hline 6 & Node5 & 11 & 97.34 & 8.305 & 2 \\
\hline 7 & 13 & 15 & 97.33 & 8.820 & 3 \\
\hline 8 & Node2 & 5 & 97.17 & 10.548 & 3 \\
\hline 9 & 4 & Node3 & 96.61 & 10.553 & 2 \\
\hline 10 & 17 & 20 & 96.61 & 11.622 & 4 \\
\hline 11 & Node8 & 9 & 96.27 & 11.981 & 2 \\
\hline 12 & 1 & 18 & 96.15 & 12.188 & 6 \\
\hline 13 & Node6 & 16 & 96.09 & 13.488 & 3 \\
\hline 14 & 2 & Node10 & 95.67 & 14.276 & 8 \\
\hline 15 & Node13 & Node7 & 95.42 & 15.749 & 3 \\
\hline 16 & Node12 & 24 & 94.95 & 16.106 & 4 \\
\hline 17 & Node12 & Node16 & 94.83 & 16.481 & 7 \\
\hline 18 & Node11 & Node9 & 94.71 & 18.665 & 7 \\
\hline 19 & Node17 & Node14 & 94.01 & 30.335 & 15 \\
\hline 20 & Node19 & Node15 & 90.26 & 38.327 & 8 \\
\hline 21 & Node18 & 10 & 87.7 & 47.581 & 23 \\
\hline 22 & Node21 & Node20 & 84.73 & 77.83 & \\
\hline 23 & Node22 & 8 & & 24 \\
\hline
\end{tabular}




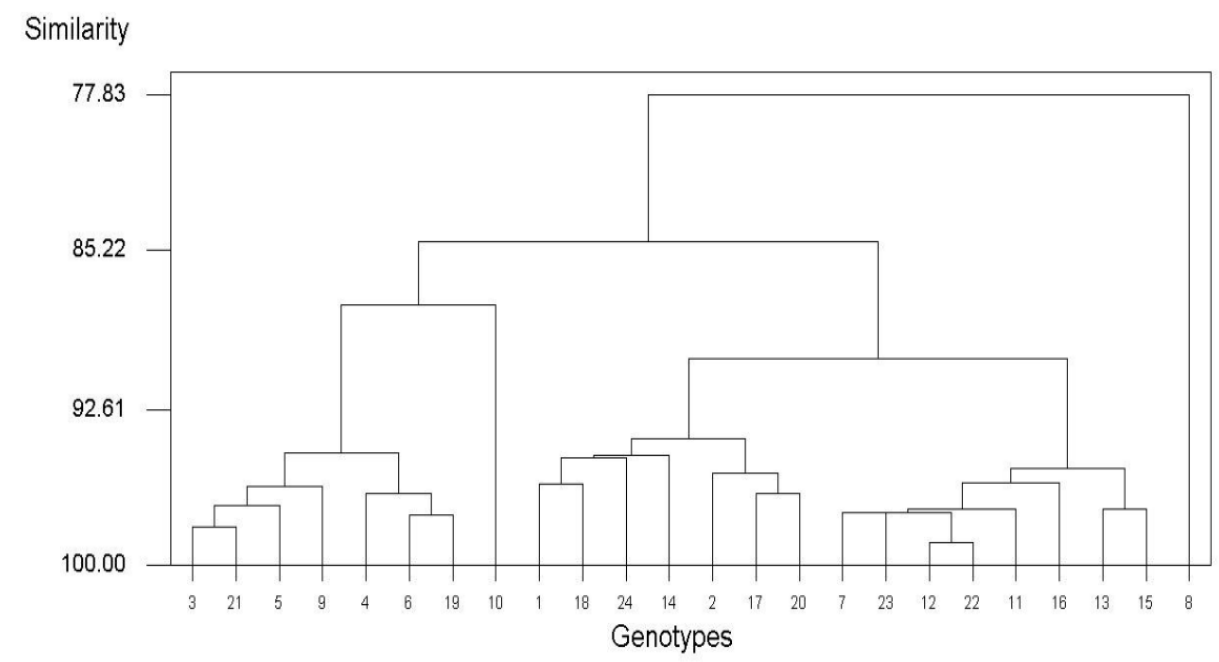

Fig.4 .Dendrogram of taxonomic similarity of twenty four cotton genotypes

1 F6 549/15

2 F8 $587 / 15$

3 F8 $598 / 15$

4 F8 $599 / 15$

$5 \mathrm{~F} 8600 / 15$

6 F8 $602 / 15$

7 F8 $604 / 15$
8 F8 $609 / 15$
9 F8 $610 / 15$
10 F8 $615 / 15$
11 F8 $620 / 15$
12 F8 $621 / 15$

\section{REFERENCES}

1. Abd El-Baky, A. M. A. 2011. Genetic studies on nitrogen use efficiency and its effect on cotton yield. Ph.D. Thesis Fac., Agric., Zagazig University, Egypt.

2. Abd El-Moghny,A.M.A. and Mariz S. Max 2015. Genotypic stability and phenotypic adaptability for some yield traits in some long staple cotton genotypes. Egypt. J. Agric. Res. 93(1);85 - 100.

3. Ali, E. Samia, Eman, M.R.M. Saleh,. and M.S.M. Srour 2012. Evaluation of some long staple cotton strains under different environments. Egypt J. Plant Breed. 16(1):41-50.

4. Anderberg, M.R. 1973. Cluster analyses for applications. Academic press, New York.

5. A.S.T.M 1998. American Society for Testing Materials. Designation, D.4605-98and 3818-98)Vol.07.No.1Easton,MD, USA.

6. Badr, S.S.M 2003 . Evaluation and genotypic stability for the hybrid (Giza $89 \mathrm{x}$ Giza 86) and some Egyptian long cotton varieties. Egypt. J. Agric. Res. 81(3), 1171- 1191.

7. Campdell, B.T. and M.A. Jones 2005. Assessment of genotype $x$ environment interactions for yield and fiber quality in cotton performance trials. Euphytica 144: 69- 78.

8. Dewdar, M. D. H. 2013. Stability analysis and genotype $x$ environment interactions of some Egyptian cotton cultivars cultivated. African J. Agric. Res. 8(41):5156-5160.

9. Eberhart, S.A and W.A. Russell. 1966. Stability parameters for comparing varieties. Crop Sci .6:36-40. 
10. El Feki, T.A., M.G.I. Beheary and A.A.A.-Akhedar. 2005. Technological and genetical estimates for yield and fiber properties of some extra - long Egyptian cotton promising genotypes . J.Agric.Res. Tanta Univ., 31(1)32-45.

11. EL -Helow, S.S.H.Sayeda., M.A.M. Allam, Hanem A. Mohamed and M.A. Abd ELGelil. 2002. Estimation of stability and genetic parameters for some characters of Egyptian extra-long stable genotypes. J. Agric. Sci. Mansoura Univ. 27(8): 53035314.

12. El-Hoseiny,H.A. 2013. Genetic evaluation of some extra long staple cotton strains (Gossypium barbadense L.,), under different environments . Egypt. J. Agric. Res. 9(4) ;1505 - 1519.

13. Gibely, H.A.Reham , AzizaM.Soultan, H.A El-Hoseiny and E.A. Amer 2015. Assessment of genetic variability and stability for some cotton genotypes. Egypt. J. plant breed. 19(6);1783-1801

14. Hair, J.F.Jr., R.E. Anderson and R.L.Tatham. 1987. Multivariate data analysis with reading. Macnillan publ. New York.

15. Khan, N. G.; M. Naveed; N. U. Islam and M, S. Iqbal 2007. Assessment of new Upland cotton genotypes (Gossypium hirsutumL.,) for yield stability and adaptability. Asian J. of Plant Sciences,6(6)1012-1015.

16. Leclerge, E.L., W.H. leonard and A.G. Clork 1962. Field Plot Technique. Burgess ppl. Co.

17. Iqbal,M.Khan, M. Jameel, M.M.Yar., Q. Javed, M.T. Aslam, B.Iqbal,Sara Shakir and A.Ahmed (2011). Study of heritable variation and genetics of yield and yield component in upland cotton (Gossypium hirsutum L.,) . Afr. J. Agric. 6 (17); 4099-4103.

18. Max, S. Mariz 2015 Increasing selection efficiency for some economic characters in cotton by using cluster analysis . Egypt. J. Plant Breed. 19(4);1075-1089.

19. Merdith, W.R., D.L. Boykin , F.M Bourland, W.D. Caldwell and B.T. Campbell 2012. Components, fiber quality, and gossypol traits in the regional high quality tests. The Journal of Cotton Science. 16; 160-169.

20. Rahoumah, M. R. A.; A.M.R. Abd El-Bary; H.M.E. Hamoud; and W.M.B.Yehia. 2008. Assessment of genetic diversity and stability for yield trails of some Egyptian long-stable cotton genotypes. Egypt. J. Agric. Res., 86 (4): 1447-1462.

21. Saleh, M. R.M. Eman. 2016. Evaluation of some Egyptian cotton genotypes by using trail $A$ and $B$ under different environments Cotton Research Institute, Agricultural Research Center, Giza, Egypt.

22. Snedecor, G. W. 1965. Statistical Methods. Iowa state Univ. Press, Ames, Iowa U.S.A.

23. Tai, G.C,C . 1971. Genotypic stability analysis and its application to potato regional traits. Crop Sci. 11:184-190. 


\title{
الثبات و التنوع الور اثي للمحصول و مكوناته في بعض التراكيب الور اثيه فى القطن المصرى
}

\author{
ساميه البلدر سيا على \\ معهد بحوث القطن - مركز البحوث الزراعية - الجيزة- مصر
}

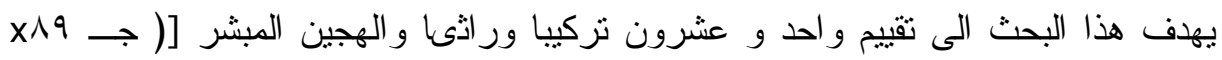

كارشنكى X X X X

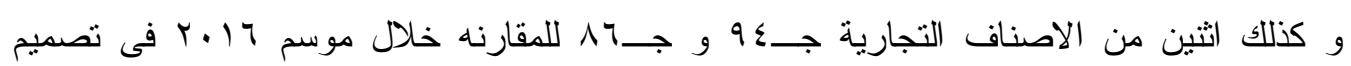
قطاعات كاملة العشو ائية فى ستة مكررات فى ست بيئات مختلفه هى كفر الثيخ - الغربية -الثرقية

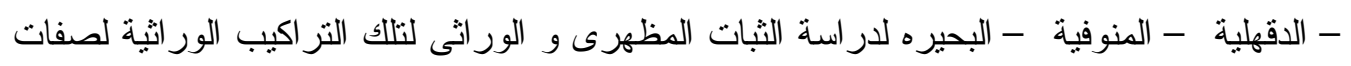

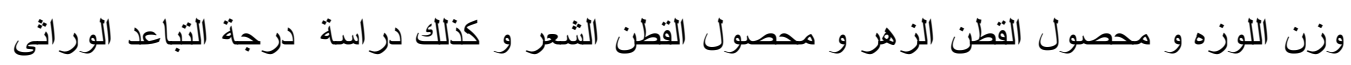
لصفات المحصول و مكوناته و الصفات التكنولوجيه ـ استخدمت ثلاث طرق التقدير الثبات المظهرى و الور اثى للصفات تحت الدر اسة و ذللك بهدف استخدام المعلومات المتاحه من هذه التقدير ات لتوجيه

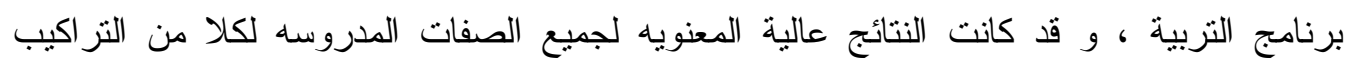

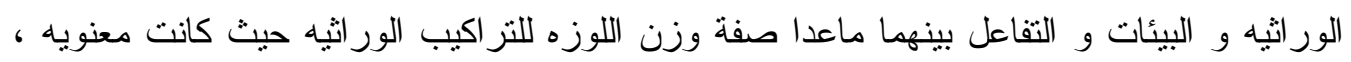

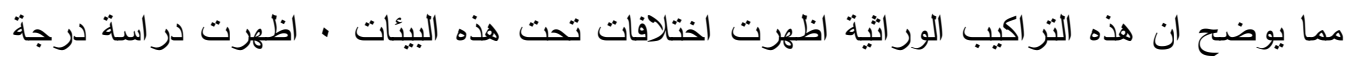

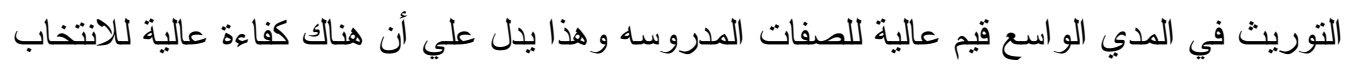

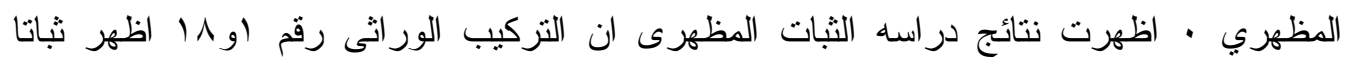
مظهريا لصفة وزن اللوزة ورقمج لصفة محصول القطن الزهر و رق رقم V لصفة محصول القطن

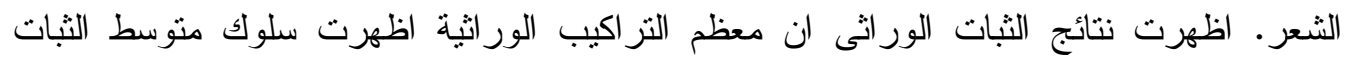

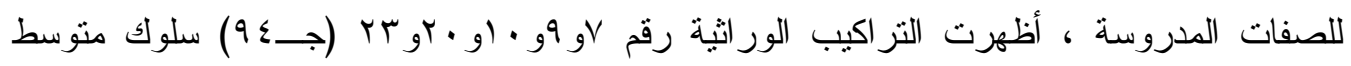

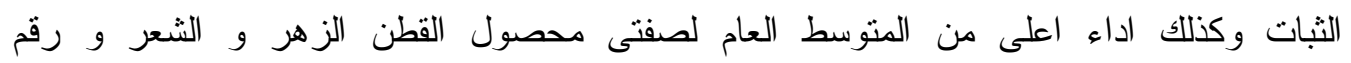

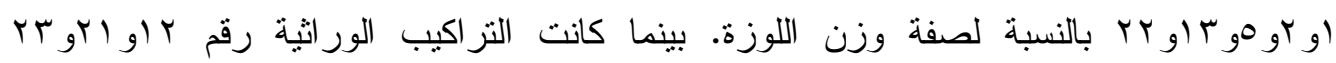

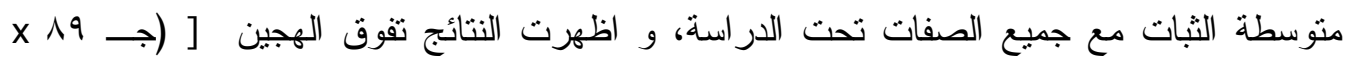

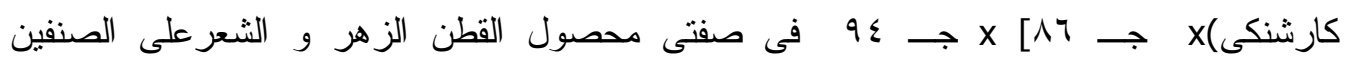

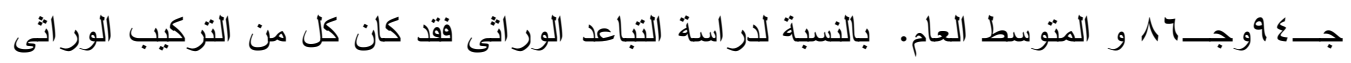

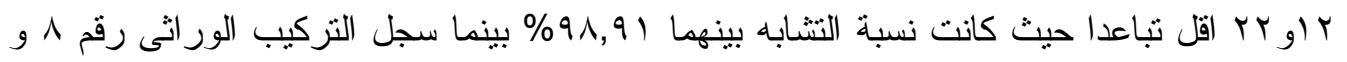

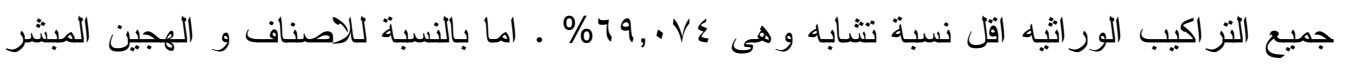

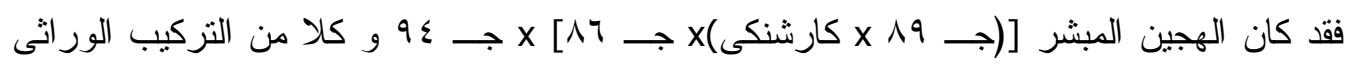

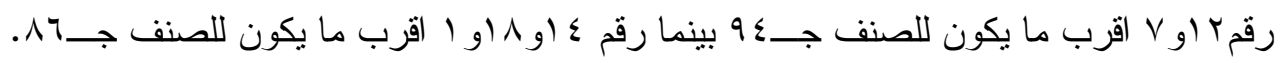

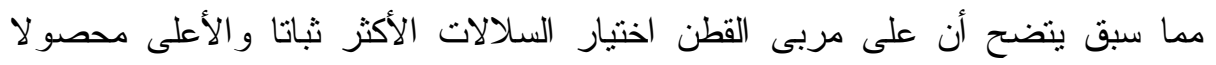

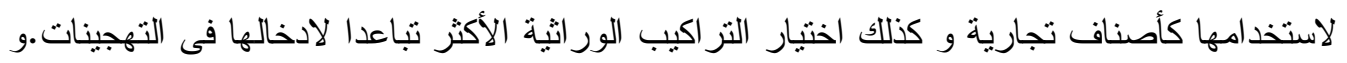

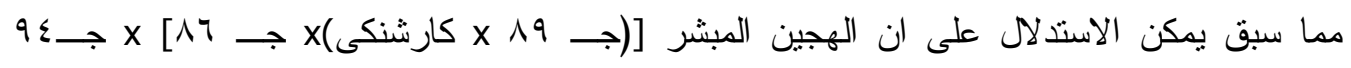

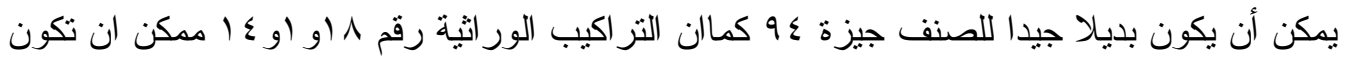

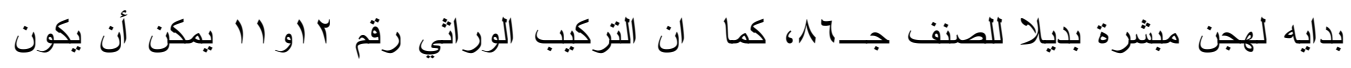

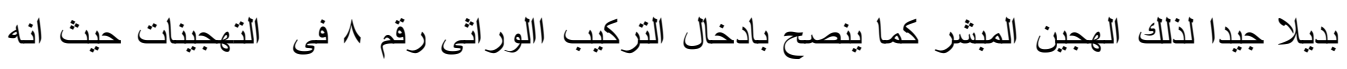
الاكثر تباعدا و متفوقا فى صفاته المحصولية. 